\title{
Utilisation of Borosilicate Glass Waste as a Micro-Filler for Concrete
}

\author{
Aleksandrs Korjakins, Genadij Shakhmenko and Girts Bumanis \\ Institute of Materials and Structures, Riga Technical University, Riga LV-1658, Latvia
}

\begin{abstract}
Glass from a light bulb is a waste product that cannot be utilised in a traditional way. This study looks into the possibilities of using lamp borosilicate glass powder as a cement replacing admixture in conventional concrete. Experimental work provides preparation of standard concrete samples and sample testing after seven and 28-day ageing periods in standard conditions. The following glass materials were used for cement replacement: rough ground glass powder, glass dust from filters (both materials were obtained from a glass treatment plant) and additionally ground glass powder. The effect of glass powder on cement setting time was studied. The experimental results indicate that replacement of cement by rough glass powder decreases the compressive strength. Fine glass particles make it possible to replace up to $20 \%$ of cement without the loss in strength characteristics. Fine glass powder offers a long-term hardening effect. The best compressive strength results were achieved by using the glass that was additionally ground for 60 minutes. Glass dust obtained from filters shows a less significant effect. Summarising the research findings it may be concluded that ground borosilicate lamp glass may be successfully applied as a micro-filler for concrete as cement replacing material.
\end{abstract}

Key words: Waste, borosilicate glass, concrete, strength.

\section{Introduction}

Glass is a silicate material that contains various oxides, the main component being silicate oxide $\mathrm{SiO}_{2}$ in an amorphous state. Several types of glass, such as soda-lime silicate, alkali-silicate and borosilicate glass are being produced in the world. The object of this research is borosilicate glass that remains after fluorescent lamp utilisation. Although a large part of glass waste nowadays is soda-silicate glass (bottle glass, window glass) and its collection and recycling procedures are worked out satisfactory, lamp glass is a specific waste product and cannot be utilised in a traditional way.

One of the possible ways of glass waste utilisation is applying it as concrete filler. A substantial research in glass waste application in concrete has been carried out in previous years [1-3]. The coarse crushed glass used as concrete aggregate can cause the alkali-silicate

Corresponding author: Aleksandrs Korjakins, $\mathrm{PhD}$, professor, research fields: building materials, recycling of waste and mechanics of solid. E-mail: aleks@latnet.lv. reactions in hard concrete, resulting in harmful expansion in interface between cement and glass surface [4, 5]. Some investigations indicate that ordinary glass can be used not only as a passive filler in concrete, but also as an active component that initiates reaction with cement minerals. It is established that ground glass particles $(<75 \mu \mathrm{m})$ may be beneficial components in concrete. Glass micro-filler initiates pozzolanic reaction and harmful expansion deformations do not occur [6]. A study of the microstructure has shown that glass powder forms a dense concrete matrix and improves concrete properties.

Modern concrete technology provides the use of complex multi-component mix systems. Special requirements for aggregate grading and especially the content of fine particles (called "micro-filler") should be taken into account (e.g., in self-compacting concrete mixes [7]). The presence of the micro-filler improves mix workability and provides a dense packing of particles in the hydrated cement paste. Dolomite, limestone powder, fly ash and silica fumes are usually 
used as micro-filler in modern concrete mixes. Micro-filler is one of the most expensive mix components, constituting as much as a half of the cement cost. Thus the replacement of the usual micro-fillers by waste products provides not only an economical gain, but contributes to environmental protection at the same time. This makes lamp glass waste utilisation in concrete a relevant task for concrete technology.

The aim of this work is to investigate the possibilities of using fine powders of borosilicate lamp glass waste as a micro-filler for conventional plastic concrete mixes.

\section{Materials Used}

\subsection{Recycled Glass Powder}

The material under examination is a glass powder obtained from a fluorescent lamp utilisation plant. The lamp recycling process includes lamp classification, glass separation, cleaning from harmful components and initial grinding. The resulting waste product is roughly ground white GP (glass powder) with the grain size smaller than $0.2 \mathrm{~mm}$. Preliminary investigation of chemical composition of the received glass waste was carried out [8], results of the chemical analysis are summarised in the Table 1 . The product contains $74.3 \%$ of silicon dioxide $\mathrm{SiO}_{2}$ and $16.6 \%$ of bore trioxide $\mathrm{B}_{2} \mathrm{O}_{3}$. Thus this material is classified as a borosilicate glass.

Tree types of bore silicate lamp glass powder materials were used in experiments:

- roughly ground GP received from recycling plant—particle size $<80 \mu \mathrm{m}$;

- GD (glass dust) obtained from filtering system of recycling process—particle size $<20 \mu \mathrm{m}$;

- additionally ground glass powder (GP60)—particle size $<20 \mu \mathrm{m}$.

Additional grinding of recycled GP was applies in order to increase glass reactivity. The material was ground in a planetary ball mill Retsch PM400 for 60 minutes, applied rotation speed $300 \mathrm{rpm}$. The obtained activated powder was used as micro filler for concrete mix preparation.

Method of laser diffraction analysis was used to determine particle size distribution of material (grading composition). Testing powder materials were dispersed in water using an ultrasonic bath. Three samples of each type of glass waste were tested.

Grading curves, which obtained by the laser diffraction method for tree types of used GP, are shown in Fig. 1. Grading analysis indicates that the rough ground material (GP) contains a wide range of particle sizes, from $2 \mu \mathrm{m}$ up to $70 \mu \mathrm{m}$, the average grain size being $26.3 \mu \mathrm{m}$. The glass dust from the filters has an average particle size of $5.0 \mu \mathrm{m}$. Grading composition analysis indicates a considerable increase in the fine particle content after additional grinding of the powder, as the average grain size of additionally ground glass is $4.0 \mu \mathrm{m}$ (Fig. 1).

\subsection{Cement and Aggregates Used}

Design of experimental mixes provides for use moderate hardening type I Portland cement CEM I 42.5 $\mathrm{N}$ as a binding agent. Chemical composition of cement is as following: $\mathrm{SiO}_{2} 22.6 \%, \mathrm{Al}_{2} \mathrm{O}_{3} 5.9 \%, \mathrm{Fe}_{2} \mathrm{O}_{3} 3.3 \%$, $\mathrm{CaO} 7.0 \%, \mathrm{MgO} 4.3 \%, \mathrm{SO}_{3} 33 \%, \mathrm{Na}_{2} \mathrm{O} 0.1 \%, \mathrm{~K}_{2} \mathrm{O}$ $2.4 \%, \mathrm{P}_{2} \mathrm{O}_{5} 0.5 \%$.

Natural local dolomite based course aggregate (gravel, density $2.70 \mathrm{~g} / \mathrm{cm}^{3}$ ) was used for mix preparation. Natural sand (dominating quartz mineral, density $2.63 \mathrm{~g} / \mathrm{cm}^{3}$ ) was used as a fine aggregate.

Table 1 Chemical composition of the glass waste.

\begin{tabular}{lcl}
\hline Components & Content (\% by mass) & Tolerance, $\pm \%$ \\
\hline $\mathrm{SiO}_{2}$ & 74.25 & 0.5 \\
$\mathrm{PbO}$ & 0 & 0.5 \\
$\mathrm{~B}_{2} \mathrm{O}_{3}$ & 16.63 & 0.5 \\
$\mathrm{Al}_{2} \mathrm{O}_{3}$ & 1.65 & 0.3 \\
$\mathrm{Fe}_{2} \mathrm{O}_{3}$ & 0.16 & 0.05 \\
$\mathrm{CaO}$ & 2.09 & 0.2 \\
$\mathrm{MgO}$ & 0 & 0.2 \\
$\mathrm{Na} 2 \mathrm{O}$ & 3.82 & 0.1 \\
$\mathrm{~K}_{2} \mathrm{O}$ & 0.93 & 0.1 \\
\hline Total & 99.48 & - \\
\hline
\end{tabular}




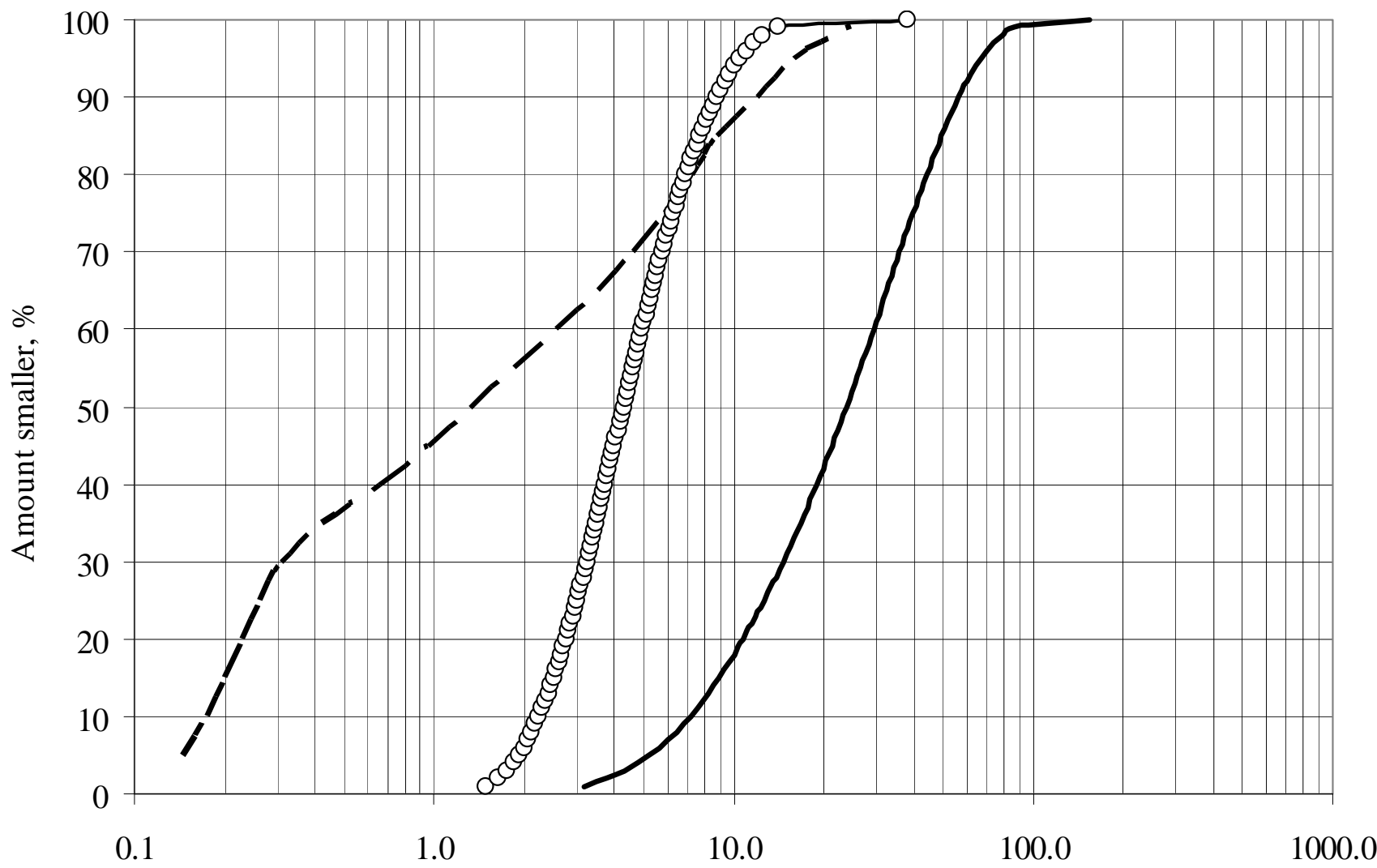

Particle size, mm

Fig. 1 Glass powder grading curves (by laser diffraction method).

Modern concretes such as self-compacting, high strength and high performance concrete are very susceptible to the grading composition of aggregate, content of micro-filler admixture and content of paste. Proportions between aggregates were calculated in order to obtain the best grading curve of the aggregate, taking into account optimum range curves in accordance with DIN 1045-2 [9]. Grading curves for used aggregates as well as optimum range curves are shown in Fig. 2.

Fine particle content was controlled in order to provide satisfactory mix workability. Recommended fine particle content $(<0.125 \mathrm{~mm})$, allowing to achieve pumpable concrete, is in a range from 375 to $450 \mathrm{~kg} / \mathrm{m}^{3}$. Experimental concrete mixes have content of fine particle $380 \mathrm{~kg} / \mathrm{m}^{3}$.

\section{Experimental Methods}

\subsection{Testing of Setting Time}

The effect of glass admixture on the cement setting time was investigated by Vicat method according to EN 196-3:1995 using Vicat apparatus. W/C (water to cement ratio of cement paste) was determined in order to produce a cement paste of standard consistence. Setting time of cement paste was controlled by means of the penetration depth of a special needle in the Vicat apparatus [10]. The testing was performed every 15 minutes, until the depth of the needle penetration was 5 $\mathrm{mm}$. The period of time from mixing the water with the dry cement until this moment is called the initial setting time. 


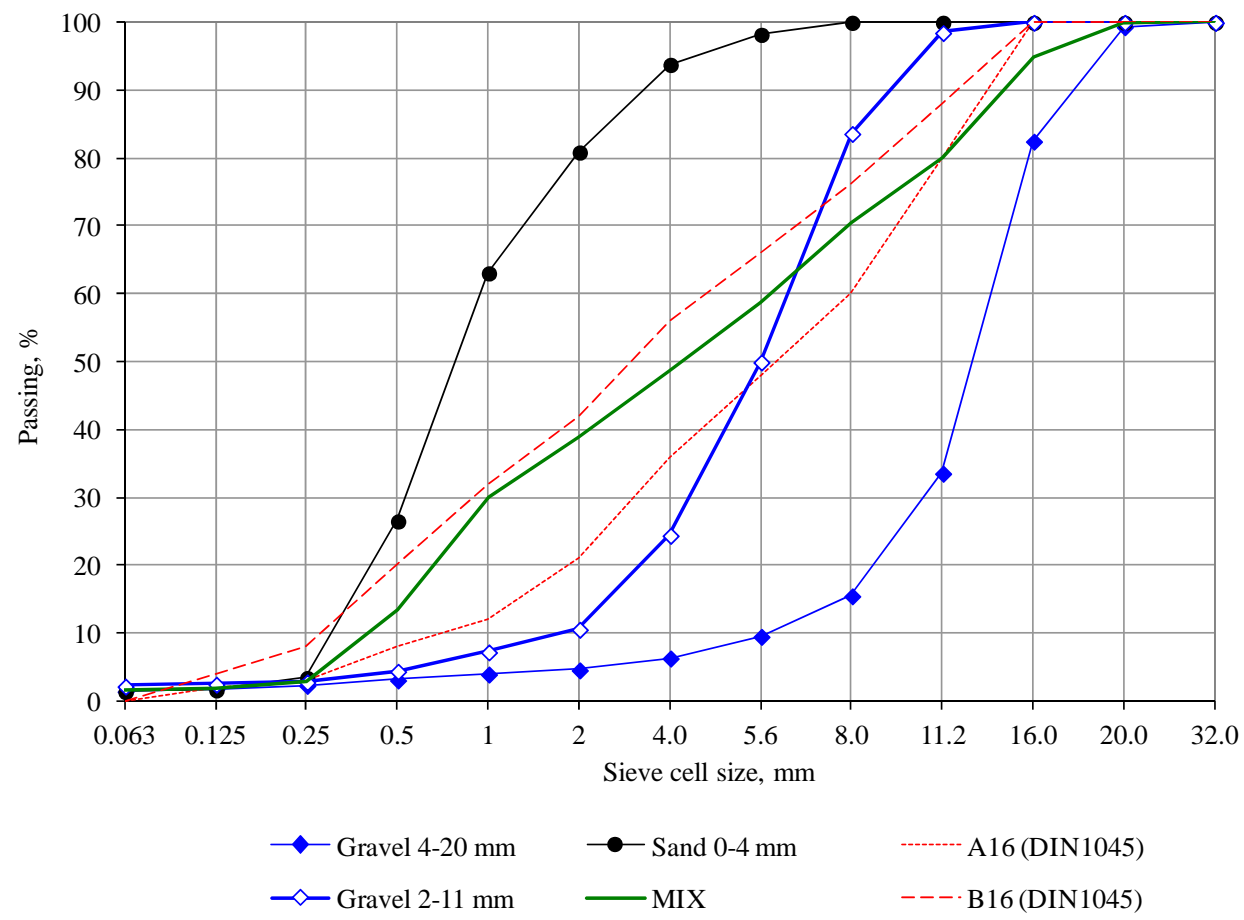

Fig. 2 Grading curves for used aggregates and optimum range.

\subsection{Concrete Mix Preparation}

Concrete mixes were prepared in a laboratory drum mixer (capacity $50 \mathrm{dm}^{3}$ ). Dry ingredients were weighed and mixed for one minute. Then, in the following minute, $80 \%$ of the desirable water content was added. Remaining water was added to the mix during the mixing process.

The mixes were tested for workability using the slump test for conventional concrete. Water dosage is selected to provide cone slump approximately constant for all mixes in the range from 150 to $170 \mathrm{~mm}$ (cone slump class S4).

\subsection{Samples, Testing Hardened Concrete}

Standard testing cubic samples $100 \times 100 \times 100 \mathrm{~mm}$ in size were produced to study the mechanical characteristics of the material. Concrete mixtures were cast into the oiled steel moulds and compacted at the vibrating table. After two days samples were dismantled. The standard hardening conditions (temperature $+20^{\circ} \mathrm{C}$, $\mathrm{RH}$ (relative humidity) $>95 \%$ ) were provided for the samples [11]. Sample measurements and testing were performed after the ageing period in the standard conditions.

The samples were tested for compression strength in conformity with Ref. [12]. A testing machine with an accuracy of $\pm 1 \%$ was used to test the compressive strength. The rate of loading was $0.7 \mathrm{MPa} / \mathrm{sec}$. The produced samples were tested after seven and 28 days. Compressive strength and density of the hardened concrete were determined.

\section{Results}

\subsection{Glass Waste Effect on the Cement Setting Time}

Setting time is one of the most important characteristics of a binding agent, as it makes the transportation and storing of a concrete mixture possible. In order to estimate the glass powder effect on the cement setting time, pure cement slurry and mixes containing $20 \%$ of glass powder and $80 \%$ of cement were tested. Rough GP, GD and additionally ground glass (GP60) were examined. The mix containing only pure cement slurry was used as reference sample. The 
mix containing $20 \%$ of silica fume (traditional high performance pozzolanic admixture) was also tested in order to obtain the additional results.

The diagrams representing the yield of penetration are shown in Fig. 3. Setting time results are summarised in Table 2.

\subsection{Concrete Mix Compositions with Cement Replaced by Recycled Glass Powder}

Laboratory mixes were designed similarly to concrete mix commonly used in the industry. Plasticising agent was not used in this case. Cement content in reference mix are $350 \mathrm{~kg} / \mathrm{m}^{3}$, the amounts of cement replacing by glass are $0,10 \%, 20 \%, 30 \%, 40 \%$ and $50 \%$.

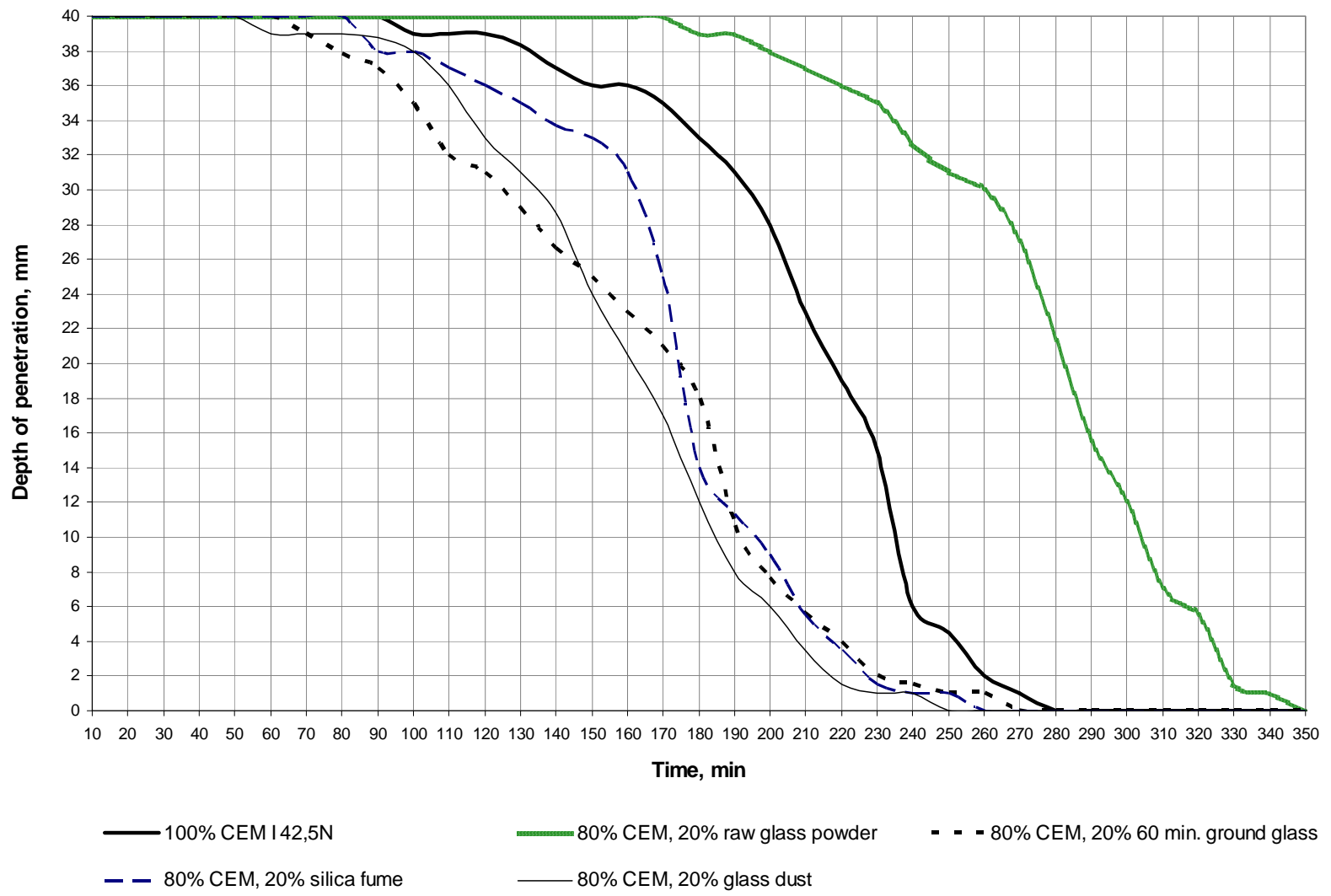

Influence of the recycled glass powder on the properties of concrete was investigated using 3 types of recycled glass material. In the first series of samples, cement was partly replaced by rough GP, obtained from a lamp recycling plant. In the second series, the additionally ground (60 minutes) ground glass powder (GP60) was used. In the third series, the lamp glass filter dust (GD) obtained from a lamp recycling plant was applied as a cement replacing material. Mix compositions and value of concrete density are summarised in Table 3.

The results of compressive strength determination are shown in Fig. 4.

Fig. 3 Diagrams of the cement mix setting.

Table 2 Setting time for cement paste containing micro-filler.

\begin{tabular}{|c|c|c|c|c|c|}
\hline & 100\% CEM I 42,5N & $\begin{array}{l}80 \% \text { CEM I } 42.5 \mathrm{~N} \text {, } \\
20 \% \text { raw glass powder }\end{array}$ & $\begin{array}{l}\text {, } 80 \% \text { CEM I } 42.5 \mathrm{~N}, 20 \\
\text { r } 60 \text { min. ground glass }\end{array}$ & $\begin{array}{l}80 \% \text { CEM I } 42.5 \\
\mathrm{~N}, 20 \% \text { silica fume }\end{array}$ & $\begin{array}{l}80 \% \text { CEM I } 42.5 \mathrm{~N} \text {, } \\
20 \% \text { glass dust }\end{array}$ \\
\hline Begin of setting, min. & 170 & 230 & 100 & 130 & 110 \\
\hline End of setting, min. & 270 & 340 & 260 & 250 & 240 \\
\hline W/C ratio & 0.33 & 0.44 & 0.42 & 0.44 & 0.44 \\
\hline
\end{tabular}


Table 3 Mix compositions and density of hardened concrete.

\begin{tabular}{|c|c|c|c|c|c|c|}
\hline Cement replacement by glass, $\%$ & 0 & 10 & 20 & 30 & 40 & 50 \\
\hline Portland cement CEM I $42.5 \mathrm{~N}$ & 350 & 315 & 280 & 245 & 210 & 175 \\
\hline Gravel 4/20 mm & \multicolumn{6}{|l|}{520} \\
\hline Gravel 2/11 mm & \multicolumn{6}{|l|}{490} \\
\hline Sand $0 / 4 \mathrm{~mm}$ & \multicolumn{6}{|l|}{730} \\
\hline Rough glass powder (GP) & 0 & 35 & 70 & 105 & 140 & 175 \\
\hline Water & 200 & 200 & 200 & 200 & 200 & 200 \\
\hline Water-Cement ratio & 0.57 & 0.63 & 0.71 & 0.82 & 0.95 & 1.14 \\
\hline Concrete density, $\mathrm{kg} / \mathrm{m}^{3}$ & 2334 & 2349 & 2331 & 2336 & 2324 & 2317 \\
\hline Ground glass powder (GP60) & 0 & 35 & 70 & 105 & 140 & 175 \\
\hline Water & 200 & 200 & 200 & 200 & 200 & 200 \\
\hline Water-Cement ratio & 0.57 & 0.63 & 0.71 & 0.82 & 0.95 & 1.14 \\
\hline Concrete density, $\mathrm{kg} / \mathrm{m}^{3}$ & 2355 & 2333 & 2337 & 2342 & 2313 & 2299 \\
\hline Glass dust from filters (GD) & 0 & 35 & 70 & 105 & 140 & 175 \\
\hline Water & 210 & 206 & 200 & 191 & 203 & 240 \\
\hline Water-Cement ratio & 0.60 & 0.65 & 0.71 & 0.78 & 0.97 & 1.37 \\
\hline Concrete density, kg/m $\mathrm{m}^{3}$ & 2360 & 2313 & 2260 & 2239 & 2211 & 2210 \\
\hline
\end{tabular}

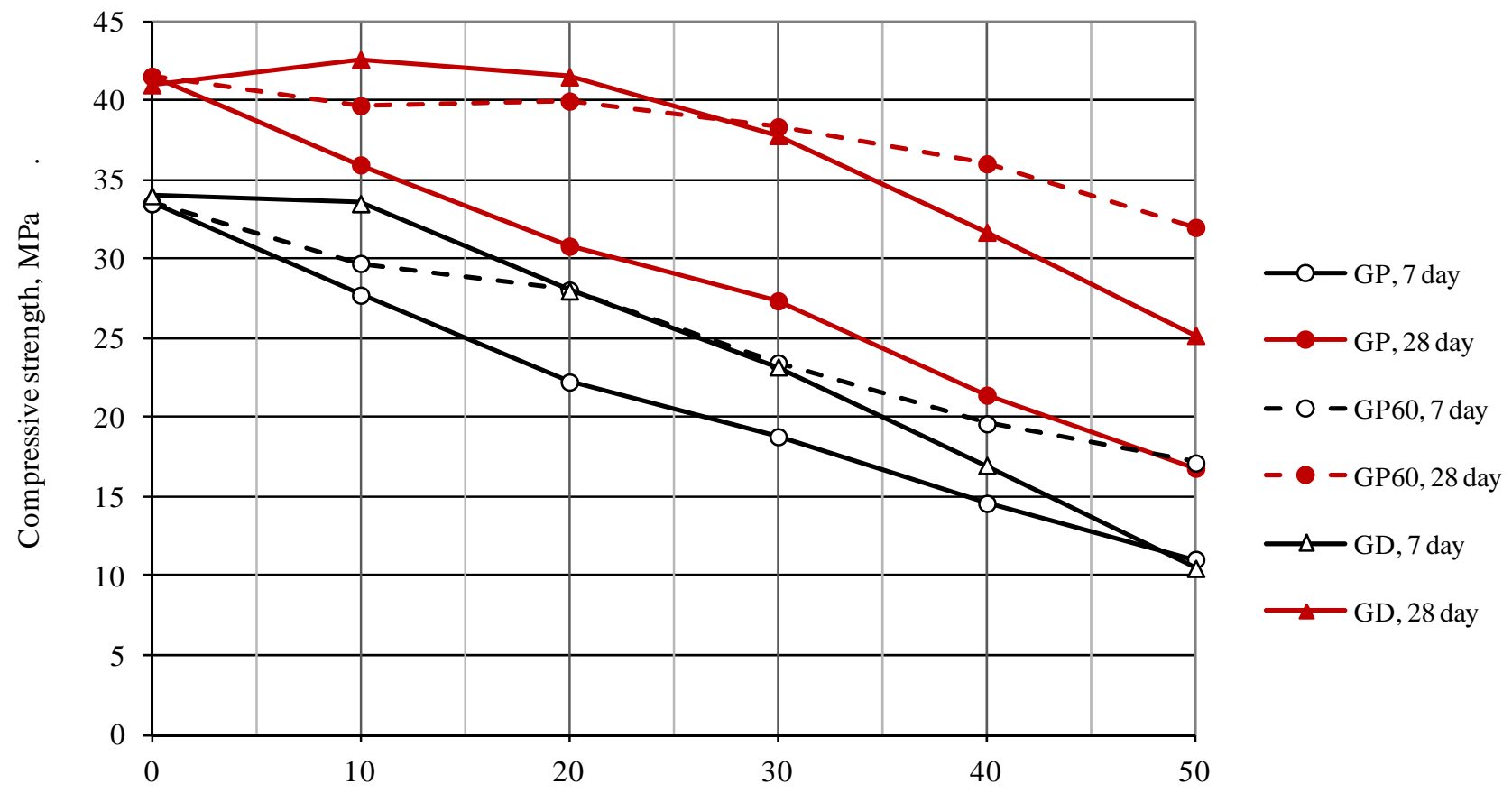

Glass, \% (replacing cement)

Fig. 4 Compressive strength of concrete after seven and 28 days hardening for different proportion cement/glass.

\section{Discussions}

Borosilicate fluorescent glass waste is studied with an aim to use this material as cement replacing admixture. It was observed that the concrete mixes containing ground glass have a more adhesive consistency compared to the conventional concrete mix. Glass powder improves mix workability, makes it more homogenous and prevents segregation. A special note should be made of the glass powder influence on 
cement setting time. Roughly ground glass increases cement setting time, but fine grained powder has an opposite, accelerating effect. It must be emphasised that concrete mixes containing all types of glass powder lose their workability very quickly (during the first hour), therefore retarding admixtures should be used. This effect asks for future research.

Required water content differs fractionally for all mixes, except for the mix with $50 \%$ replacement by glass dust (where water consumption has increased by 20\%).

Glass grinding effect on the mix density is negligible (mostly within 1\%). A far more noticeable decrease in density (up to $5 \%$ or $120 \mathrm{~kg} / \mathrm{m}^{3}$ ) takes place if cement is replaced by additionally ground glass (in amount $>40 \%$ ) and glass dust (in amount $>10 \%$ ). Density decreasing effect may be explained by additional air content in concrete mix. Such effect may be caused by concrete compacting or due to additional air entraining. This phenomenon should be investigated in future research.

Experimental results indicate a decrease of compressive strength of concrete in seven and 28 days when part of the cement is replaced by the rough ground glass filler (GP). Thus the roughly ground glass powder acts rather as a passive micro-filler.

In the case of additionally activated glass powder (grounded for $60 \mathrm{~min}$.) or glass dust usage, an increasing in compressive strength was observed after 28-day hardening. This effect may be explained by the activation of pozzolanic reactions caused by glass additional grinding and increasing of specific surface. Compressive strength was observed to decrease in all cases after seven days, it may be explained by low intensity of pozzolanic reactions in early hardening stage.

Experimental results indicate that it is possible to achieve very economical ("green") concrete compositions with lowered cement content. For example, when replacing $30 \%$ of cement by fine-grained glass powder, the 28-day compressive strength decreases only by $10 \%$ (cement content in this case $245 \mathrm{~kg} / \mathrm{m}^{3}$ ).

Obtained data complains with results of other research mentioned in literature. The phenomena of pozzolanic activity has mentioned in several research concerning glass waste utilisation.

For example, author [5] has been investigated both short-term and long-term effect of sheet glass powder introducing in cement mortar mix. It is emphasised that reduction in 28 day strength is short-term effect, because in such short periods pozzolanic effect is not evident. Author Shayan proved that samples containing sheet glass powder continue to develop strength with the time (after 90 and 270 days), indicating pozzolanic reactivity.

Other authors have been investigated the effect of glass powder fineness on strength development of concrete [3]. Ground soda lime glass was used as partial (30\%) cement replacement. Ground glass having different particle size gradation was used (38, 75 and $150 \mu \mathrm{m})$. The results indicates low strength development for mix containing rough $(150 \mu \mathrm{m})$ glass powder and considerable strength gain after 28 and 90 days for mix containing $38 \mu \mathrm{m}$ fine glass powder.

In the case of this investigation particle size of additionally ground glass (GP60) and glass dust (GD) was smaller than $20 \mu \mathrm{m}$. Summarizing recorded effect of glass particle fineness on concrete strength and taking into account review of literature, glass particle size smaller than 20-30 $\mu \mathrm{m}$ may be recommender to achieve good pozzolanic reactivity.

At the same time, it should be noted that the possible other effects of cement replacement by recycled glass was not yet investigated in presented work. For example: chemical resistance, frost resistance, water permeability, shrinkage, creep and other factors that determine long-term performance of material. Hygienic and ecological estimation of application of lamp glass recycling products as concrete micro-filler must also be carried out carefully. Behaviour of 
long-term hardened concrete ( $>100$ days), containing fluorescent glass, also will be investigated in future.

\section{Conclusions}

Borosilicate glass powder improves concrete mix workability, makes the mix more adhesive and homogenous.

The properties of fresh concrete mix and the properties of hardened concrete depend considerably on the fineness of glass powder.

Roughly ground glass increases cement setting time. At the same time, additionally ground glass powder and glass dust considerably accelerate the cement setting processes. A loss of mix workability takes place in the first hour for all types of glass powders.

Cement replacement by a roughly ground borosilicate glass powder reduces compressive strength in seven and 28 days. Roughly ground glass powder acts as inert micro-filler.

Additionally (60 min) ground glass powder as well as glass dust demonstrate properties of active micro-filler that performs a long-term hardening effect. Cement replacement by fine grinded powder reduces compressive strength in seven days and demonstrates considerable strength gain in 28 days.

Up to $20 \%$ of cement may be replaced by activated glass powder (or filter dust) without reducing compressive strength in 28 days.

Durability and physical properties of concrete containing glass powder must be investigated in the future in a more detailed way.

Glass powder may be used as a good pozzolanic admixture improving physical and mechanical characteristics of concrete. Recommended particle size of glass powder to obtain the best effect - smaller than $20 \mu \mathrm{m}$

\section{Acknowledgement}

The financial support of the Ministry of Education and Science of the Republic of Latvia and the ERAF project "Nr. 2010/0286/2DP/2.1.1.1.0/10/APIA/VIAA/033, high efficiency nano-concretes” is acknowledged.

\section{References}

[1] W. Jin, S. Meyer and S. Baxter, Glassconcrete-concrete with glass aggregates, ACI Material Journal 97 (2) (2000) 208-213.

[2] N. Schwarz and N. Neithalath, Influence of a fine glass powder on cement hydration: Comparison to fly ash and modelling the degree of hydration, Cement and Concrete Research 38 (2008) 429-436.

[3] G. Shakhmenko, A. Korjakins and G. Bumanis, Concrete with microfiller obtained from recycled lamp glass, in: Proceedings of the 10th international Conference on Modern Building Materials, Structures and Techniques, Vilnius, Lithuania, 2010, pp. 280-284.

[4] Y. Shao, T. Lefort, S. Moras and D. Rodriguez, Studies on concrete containing ground waste glass, Cement and Concrete Research 30 (2000) 91-100.

[5] A. Shayan, Value-added utilisation of waste glass in concrete, in: Proceedings of IABSE Symposium, Melbourne, Australia, 2002.

[6] A. Shayan and A. Xu, Performance of glass pozzolanic material in concrete: A field trial on concrete slabs, Cement and Concrete Research 36 (2006) 457-468.

[7] R. Siddique, Waste Materials and By-Products in Concrete, Springer, Berlin, 2008, p. 427.

[8] H. Okamura and K. Ozawa, Mix design for self-compacting concrete, Concrete library of JSCE 25 (1995) 107-120.

[9] LVS EN 12390-2, Making and Curing Specimens for Strength Tests, Testing Hardened Concrete-Part 2, 2000.

[10] LVS EN 12390-3, Testing Hardened Concrete-Part 3: Compressive Strength of Test Specimens, 2002.

[11] LVS EN 196-3, Methods of Testing Cement, Determination of Setting Time and Soundness, 1995.

[12] DIN 1045-2, Concrete, Reinforced and Prestressed Concrete Structures-Part 2: Concrete-Specification, Properties, Production and Conformity-Application Rules for DIN EN 206-1, 2008. 